\title{
Impact assessment of simultaneous operation of photovoltaic and cogeneration power plants on industrial distribution system
}

\author{
B. Koti Reddy, Amit Kumar Singh
}

School of Electronics and Electrical Engineering, Lovely Professional University, Jallandhar, India

\begin{tabular}{l} 
Article Info \\
\hline Article history: \\
Received Jun 21, 2021 \\
Revised Sep 28, 2021 \\
Accepted Sep 30, 2021 \\
\hline Keywords: \\
Cogeneration captive power \\
plant \\
Design adequacy \\
Microgrids \\
Renewable energy \\
Solar irradiance conditions
\end{tabular}

Corresponding Author:

B. Koti Reddy

School of Electronics and Electrical Engineering

Lovely Professional University

Jalandhar-Delhi, Grand Trunk Rd, Jallandhar, Punjab 144001, India

Email: kotireddyb@ieee.org

\begin{abstract}
Industries with co-generation plants face unprecedented problems due to penetration of renewable energy systems such as solar power on their existing distribution networks. These problems are caused by intermittent solar power. To this end, this paper provides a detailed investigation of the effects due to sudden changes in solar power on an existing industrial distribution network connected to co-generation plants. Moreover, the case studies in this work consider simultaneous operation of a large industry having co-generation captive power plant and large scale solar photovoltaic power plant. The real-time field data for the past three years are used to check the performance of solar photovoltaic power plant, load management, power quality and other concerning issues on the distribution network. In addition to the real-time data, the simulations were performed for the solar power output under different solar irradiance conditions. Moreover, these simulations are used to assess photovoltaic integration effects on a distribution system having a co-generation captive power plant. Finally, this paper put forward photovoltaic integration guidelines to industries and policymakers interested to carry out the integration studies in the future.
\end{abstract}

This is an open access article under the CC BY-SA license.

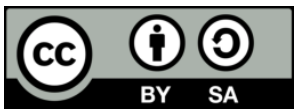

\section{INTRODUCTION}

Renewable energy systems (RESs) are exhaustive and supporting the global power demand to the extent possible. Out of the available RESs such as solar, wind, hydro, and biogas, the significant share goes to solar power, as on date. Many RESs are being constructed at the point of use and connected to the local power distribution network; hence, the name of distributed energy resources (DERs) has aroused [1]. The present increased utilization of electrical energy globally, causing more transmission and distribution energy losses in addition to peak load hour congestion and unwanted load shedding, which can be off-set by the DERs. Co-generation captive power is broadly known as the generation of electrical power by industry from either its available thermal energy (e.g., steam) or other forms of energy for its self-use [2]. This type of captive power generation, known as distributed generation, is reducing the demand on the electrical grid as well as improving the efficiency of the industry, due to utilization of waste steam, hot liquids, and effluents. This, in turn, is conserving the natural resources, e.g., coal, and thus protecting the environment. RESs, especially of solar energy, are low energy density and intermittent, which makes them fast responding to environmental changes concerning slow responding conventional power plants such as coal-fired thermal units [3]. Thus, affecting the stability of the distribution networks, precisely, the distribution networks can 
have a substantial voltage fluctuation, which is undesirable for the reliable operation of an industry. Also, the DERs, when connected to distribution systems, contribute to the existing distribution network fault currents, in case of any fault in their internal power network. These additional fault currents will be seen by the existing switchgear circuit breakers and protective relays, and thus creates the doubts of design adequacy of switchgear equipment as well as reliability of the protection system. Most of the DERs (e.g., solar) absorbs reactive power from the distribution networks in grid-connected mode and also injects harmonics into the power distribution networks, due to the presence of power electronic converters. Leveraging the advancements in smart grids, the penetration rate of RESs is gaining momentum, with a share in total generation capacity of $33.3 \%$ in 2018 to $34.7 \%$ in 2019 [4]. Hence the joint operation of co-generation captive power plants and DERs is more challenging for practitioners due to the fact that the high penetration of RESs may degrade the efficiency of co-generation captive power plants.

As on date, no established codes, guidelines, and policies of DERs, especially on co-generation captive power plants, are available in terms of the share and mitigation techniques of their adverse effects. However, Institute of Electrical and Electronics Engineers (IEEE) 1547.7-2013 [5] has given some guidelines to make researchers understand the impacts of DERs integration on distribution networks, but not entirely done till date from a practical perspective. Also, the IEEE 1547-2018 [6] and IEEE 1547a-2020 [7] specified the requirements and response during normal and abnormal conditions. Furthermore, little work is done till date concerning DER impact study on co-generation captive power plants. Hence there is an urgent need to study the impact of DERs on existing industrial power distribution network with captive co-generation, and this stands as the primary subject of this paper. With the IEEE guidelines, as mentioned above from operational perspective, this paper gathered inputs from the field data and thoroughly studied the impacts of simultaneous operation of DER and co-generation captive power plants on the existing distribution network in large industry setup. For this work, the case of the chemical industry, having its own co-generation captive power plant (CCPP) with solar photovoltaic (PV) power plant (SPP) is considered.

\section{LITERATURE REVIEW}

It is a known fact that the existing conventional power distribution networks were designed for unidirectional power flow but nor for bidirectional caused due to DERs. The IEEE 1547.7-2013 has provided certain guidelines for impact study from a technical perspective such as engineering parameter criteria and data requirement to conduct study and interpret the results. It has stressed the need to study the effects in terms of voltage fluctuations, increased fault currents and false trip of relays, reactive power injection or absorption and voltage regulation, system stiffness or weakness, design adequacy of equipment, and arc flash hazard study. An extensive study of literature is done on the selected topic to know the research done in the past. It has helped in knowing the up-to-date work done by various researchers and identify the research gaps therein. The brief summary of literature review is given as follows:

Mansouri et al. [8] has reviewed the technical challenges due to large scale PV integration such as voltage stability and limit violations. The above reference outlined the power system stability during fault conditions and the need for intelligent systems. Badal et al. [9] have described the usefulness of renewable energy and the integration challenges like voltage and frequency deviations and have suggested for special protection schemes and control issues. Alzyoud et al. [10] have analysed the impacts of integration of solar farms, such as voltage profile, power losses and short circuit levels with simulations by electrical transient analyzer program (E-TAP) software and suggested to install PV power plants near the load conters. The protection strategies to mitigate DER impact on existing distribution networks are studied in [11]. The impact of RESs as co-generation power plant on power system network are discussed in [12] with a suggestion to manage reactive power requirements. The authors have simulated a $6.3 \mathrm{MW}$ co-generation power plant. The effects of bidirectional power flows and protection strategy on inverter-based microgrids are discussed in great detail in [13] and developed a new protection strategy. An expert group on recommended practices for wind and PV integration [14] has provided the information on how to do integration study. The report of this group, has presented the main points like load scheduling, dispatch, reactive power, and transients, for future studies. Adebiyi et al. [15] have modelled and investigated the impact of the distribution grid-connected PV system having variable loads under various weather conditions. They have concluded that the varying energy demands were efficiently managed with suitable maximum power point tracking (MPPT) control methods. In coal fired steam power plants, maintenance of constant outlet steam pressure irresptve of load is an important aspect with proper control in mentioned by the authors in [16].

Although, the aforementioned literature survey reveals that there are certain technical issues such as power quality and relay protection issues with the higher penetration of renewable energy (mainly solar photovoltaic). The major gaps in experiments and real-time field application still exists and the need for policies and grid standards on RESs integration issues are required. The contribution of this work is given below: 
- This work adopts PV module using single-diode principle and verifies the model accuracy using standard PV simulation software.

- This work considers thorough case studies to analyze the performance of solar PV power along with co-generation plant connected to distribution network. These case studies present the effects of PV integration on distribution network power flow considering randomness, fault current and harmonic content in the PV systems using real-time data.

- Finally, this work put forward PV integration guidelines considering co-generation captive power plants in the existing distribution networks. These guidelines help policymakers and industries for their improved business plans and can be a stepping stone for the future microgrids modeling, design, and analysis.

The organization of the paper is given next. Section 3 discusses the modeling of PV module. Section 4 presents the details of industry and its operational strategies. The performance analysis of the PV system along with captive co-generation is presented in section 5. Section 6 presents the impacts of PV system along with captive co-generation using simulations conducted in modeling software E-TAP, and conclusions with future work are drawn in section 7.

\section{MODELING OF PV MODULES}

The solar power plant (SPP) consists of many numbers of photovoltaic (PV) modules connected in series (strings) and parallel (arrays) to get the desired voltage and active power. PV modules need to be modeled to know its behavior under different ambient conditions. A solar PV cell is a semiconductor on which research work on its mathematical modeling is being done continuously by many researchers with different techniques. However, the model suggested in [17] is being widely used, in which the PV cell operation is explained with the help of Shockley's simple diode model. The current supplied by the PV module (I) and the photo current (Iph) in amperes are given by the following expression (1):

$$
I=I_{p h}-I_{0}\left(\exp \left(\frac{q\left(V+I R_{S}\right)}{N_{c s} \Gamma k T_{c}}\right)-1\right)-\frac{\left(V+I R_{S}\right)}{R_{p}}, \quad I_{p h}=\frac{G}{G_{r e f}}\left(I_{p h, r e f}+\mu I_{s c}\left(T_{c}-T_{c, r e f}\right)\right.
$$

where $\mathrm{G}$ and Gref are the effective and reference irradiance in $\mathrm{W} / \mathrm{m}^{2}, \mathrm{~T}$ and $\mathrm{Tc}$,ref are the effective and reference cell's temperature in ${ }^{0} \mathrm{~K} ; \mu$ Isc represents the temperature coefficient of the short-circuit current in $\mathrm{A} /{ }^{\circ} \mathrm{C}$; Io is the diode reverse saturation current in amps; $\mathrm{q}$ denotes the charge of the electron which is given by $1.602 * 10^{-19}$ Coulombs and $\mathrm{k}$ is the Boltzmann constant, which is given by $1.381 * 10^{-23} \mathrm{~J} / \mathrm{K} ; \mathrm{V}$ denotes the voltage at the terminals of the module in volts; Rs denotes the series resistance in Ohms; Rp is the shunt resistance in ohms; Ncs represent the number of cells in series; finally, $\Gamma$ denote the diode quality factor which lies between 1 and 2 ; which is generally taken as 1.3 .

\subsection{PV-module simulation model}

For simulation purpose, the PV module REC255PE manufactured by the renewable energy corporation, Singapore [18] used in the case studies considered in this work. The type of the selected module has a total 60 multi-crystalline cells in series of three strings; each string has 20 cells and three bypass diodes. In general, the PV module details such as open circuit voltage, maximum power point voltage, nominal current, short circuit current, temperature coefficient of power and voltage at standard test conditions (STC), air mass (AM) of 1.5, cell temperature of $25^{\circ} \mathrm{C}$ and normal operating cell temperature (NOCT), wind speed of $1 \mathrm{~m} / \mathrm{sec}$, ambient temperature of $20{ }^{\circ} \mathrm{C}$, and cell temperature of $45.7^{\circ} \mathrm{C}$ specified by the PV manufacturers. Table 1 highlights the details of the selected PV module. The main variables in the PV module are solar irradiance and operating temperature. There are a few numbers of PV design and simulation software available in the market, such as PVsyst, PV F-Chart, pvPlanner, RETscreen, and solar pro. Most of them are made for either academic purpose or limited use and do not have full modeling, shading and end-user interface. On the other hand, PVsyst is designed to be used by architects, engineers, and researchers. It is also a handy educative and field-oriented tool, which includes system design, sizing, shading analysis, simulation and results [19]. Besides, it can import meteorological data, as well as individual data from many different sources and the unique feature of bi-facial model estimations.

\subsection{Validation of PV-module model}

Figures 1-4, respectively, show the graphical results of the above simulations. The PV module model by Shockley's simple diode is validated using PVsyst for the following conditions:

- I-V Characteristics with varying irradiance at constant temperature.

- P-V Characteristics with varying irradiance at constant temperature.

- I-V Characteristics with varying temperature at constant irradiance.

- P-V Characteristics with varying temperature at constant irradiance. 
Table 1. Details of the PV module for case studies considered in this work

\begin{tabular}{clcccc}
\hline S. No. & \multicolumn{1}{c}{ Parameter } & Symbol & Unit & Value at STC & Value at NOCT \\
\hline 1 & Nominal power & Pmpp & Watts & 255 & 185 \\
2 & Nominal power voltage & Vmpp & Volts & 30.5 & 28 \\
3 & Nominal power current & Impp & Amps & 8.42 & 6.68 \\
4 & Open circuit voltage & Voc & Volts & 37.6 & 34.8 \\
5 & Short circuit current & Isc & Amps & 8.95 & 7.18 \\
6 & Panel efficiency & $\eta$ & $\%$ & 15.5 & - \\
7 & Temperature coefficient of Pmpp & - & $\% /{ }^{\circ} \mathrm{C}$ & -0.4 & - \\
8 & Temperature coefficient of Voc & - & $\% /{ }^{\circ} \mathrm{C}$ & -0.27 & - \\
9 & Temperature coefficient of Isc & - & $\% /{ }^{\circ} \mathrm{C}$ & 0.024 & - \\
10 & Irradiance & $\mathrm{G}$ & $\mathrm{W} / \mathrm{m}^{2}$ & 1000 & 800 \\
\hline
\end{tabular}

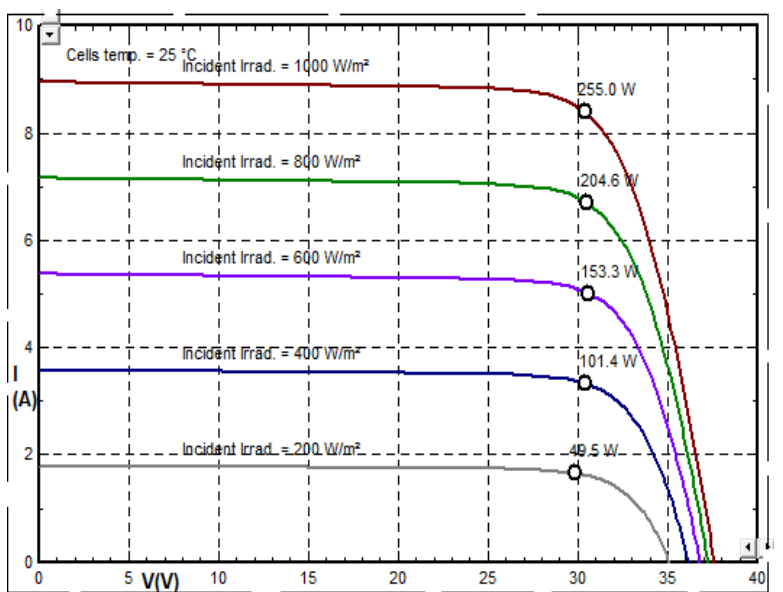

Figure 1. I-V Characteristics with varying irradiance at constant temperature

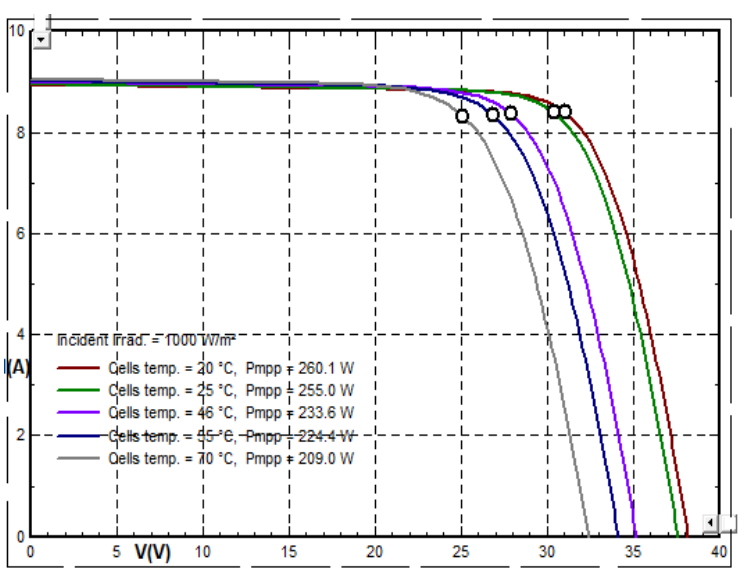

Figure 3. I-V Characteristics with varying temperature at constant irradiance

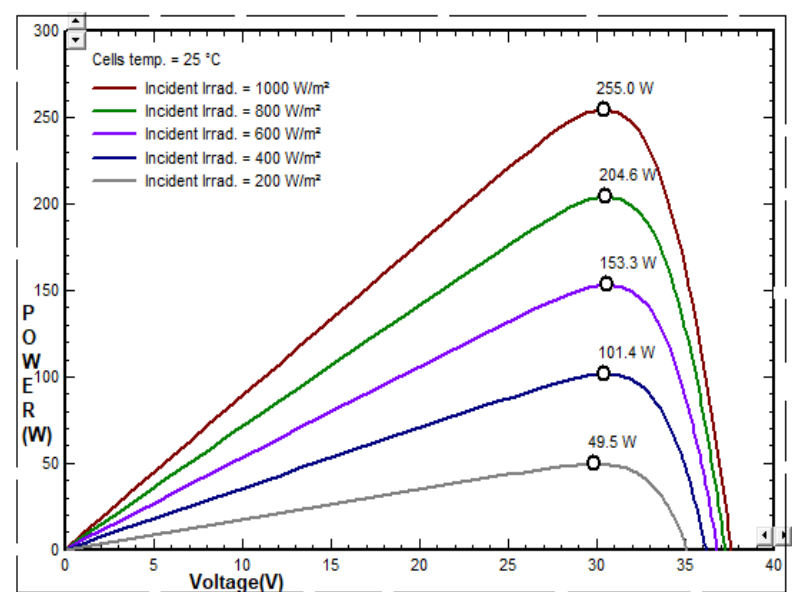

Figure 2. P-V Characteristicswith varying irradiance at constant temperature

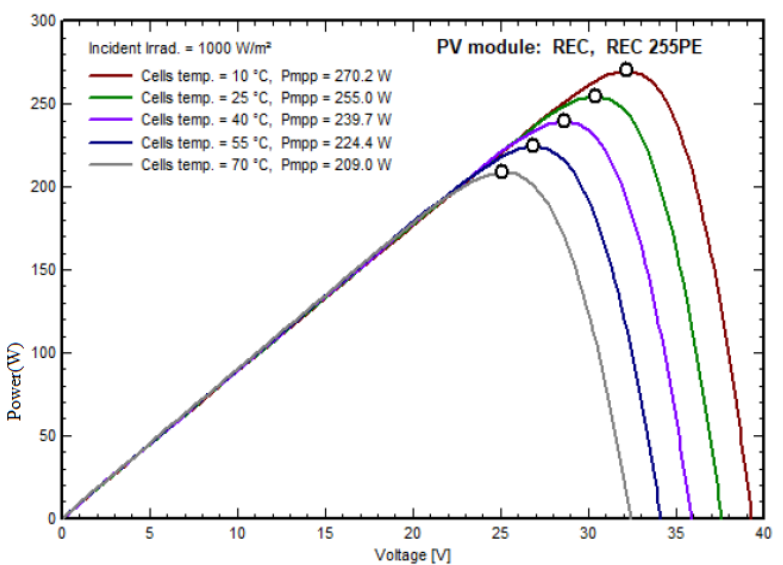

Figure 4. P-V Characteristics with varying temperature at constant irradiance

The simulation results validate the relationships between I-V and P-V characteristics of PV module by Shockley's simple diode model (1). Furthermore, we verify the accuracy of simulated results using (1) by comparing with the reference values given by the manufacturer (Mfr.) of SPV modules; Table 2 provides approximation error details. The approximation error can be defined as follows (2):

$$
\text { Approximation error }=\frac{\text { value in } Y_{1}-\text { value in } Y_{2}}{\text { value in } Y_{2}}
$$

where $\mathrm{Y}_{1}$ and $\mathrm{Y}_{2}$ correspond to reference value specified by the manufacturer (for STC and NOCT) and value obtained in the simulation using (1) respectively. Based on the above results, we claim that the error is very 
low and therefore, the Shockley's simple diode model can be used as a baseline for large-scale PV integration studies.

Table 2. Comparison between simulation and actual results using Shockley's simple diode model

\begin{tabular}{ccccccc}
\hline \multirow{2}{*}{ Parameter } & \multicolumn{2}{c}{ Ref. value of Mfr. } & \multicolumn{2}{c}{ Simulation result using (1) } & \multicolumn{2}{c}{ Approximation error } \\
& STC & NOCT & STC & NOCT & STC & NOCT \\
\hline Pmpp & 255 & 185 & 255 & 187.6 & 0 & 0.014 \\
Vmpp & 30.5 & 28 & 30.5 & 28 & 0 & 0 \\
Impp & 8.42 & 6.68 & 8.42 & 6.7 & 0 & 0.0003 \\
Voc & 37.6 & 34.8 & 37.6 & 35 & 0 & 0.0057 \\
Isc & 8.95 & 7.18 & 8.95 & 7.2 & 0 & 0.0028 \\
\hline
\end{tabular}

\section{INDUSTRY DESCRIPTIONS FOR CASE STUDIES CONSIDERED}

This section describes the power distribution network, co-generation captive power plant (CCPP) set up, and the solar photovoltaic power plant (SPP) details considered in the case studies. For the case studies considered in this work, we chose a known large-scale continuous process chemical industry, which has both CCPP and solar photovoltaic power plant (SPP). The process plant requires high-pressure steam of $32 \mathrm{~kg} / \mathrm{cm}^{2}$ at higher temperatures of order of $240{ }^{\circ} \mathrm{C}$. The total power requirement of industry is $36 \mathrm{MW}$ out of which $30 \mathrm{MW}$ is required during normal operation of the industry. The remaining $6 \mathrm{MW}$ is always necessary to support base loads in plants such as water system and ventilation. Since the considered industry is continuously operated, therefore, the net load of the plant is almost constant irrespective of seasons and time. Moreover, some of the loads such as air conditioning and service water pumps, which are 'on' at day time are turned 'off' during the night. However, the lighting load, which is essentially required in dark hours, will off-set the net load during the night time. The authors ahs verified the past three years load profile of the industry and concluded the same. Figure 5 depicts the power schematic diagram of the industry whose operational philosophy of same is described in subsequent sections.

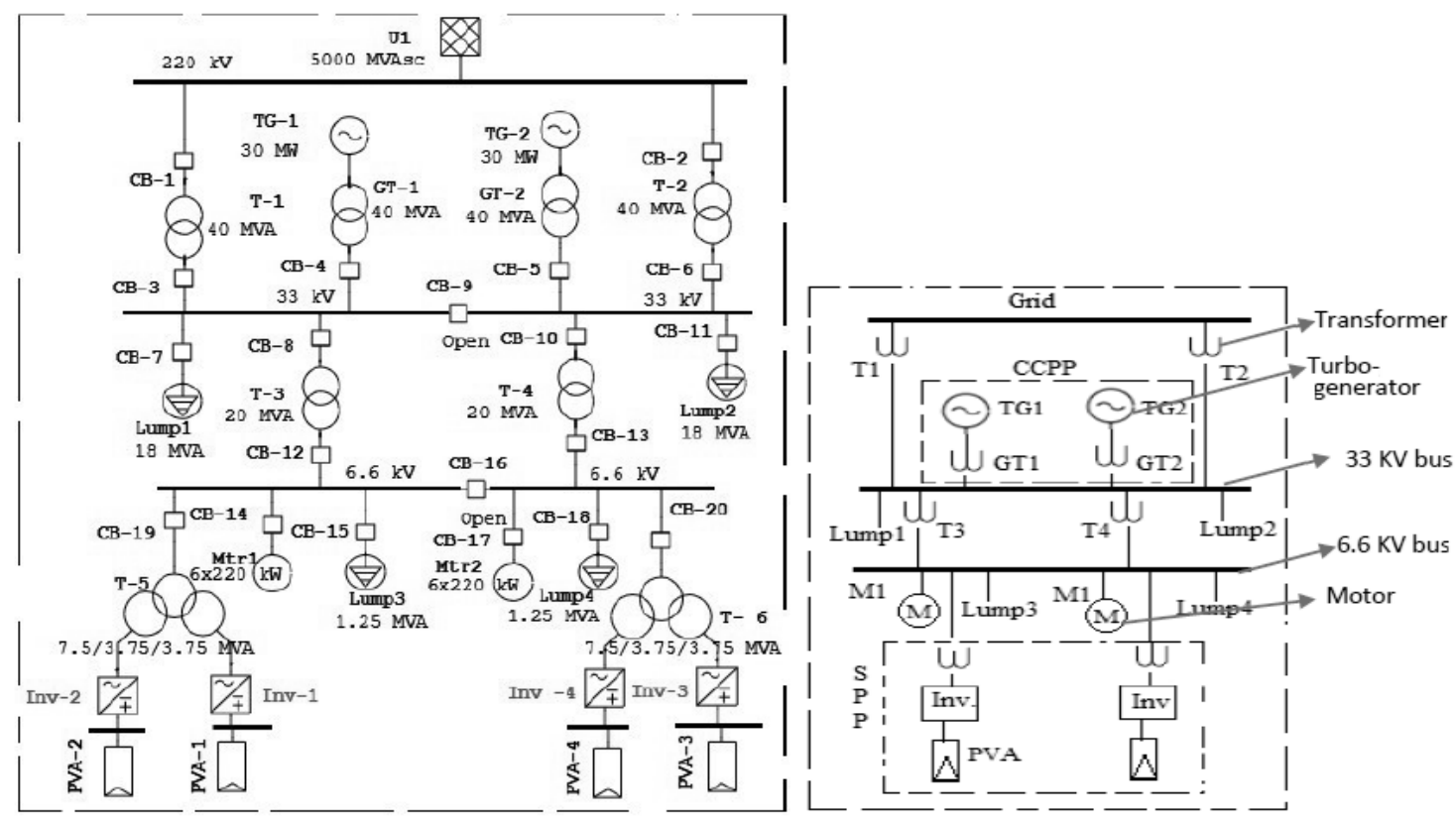

Figure 5. Power supply schematic diagram including CCPP and SPP

\subsection{Co-generation power plant}

The CCPP with two steam boilers and turbo generators (TGs) are installed in the considered industry with coal as the fuel for boilers. The Steam generator consists of radiant boiler with integral super heaters, forced flow section and tubular air heater with two forced draft and two induced draft fans. The turbines are of extraction condensing type with turbo generators (TGs). The TGs are 2-pole, 3-phase, aircooled and connected to the steam turbine directly. Their maximum output is rated at $30 \mathrm{MW}$ (35.29 MVA at 0.85 power factor) at $11 \mathrm{kV}$ levels, which is stepped up to $33 \mathrm{kV}$ level. Also, CCPP is connected with a utility grid for start-up purpose at $220 \mathrm{kV}$ levels with $220 / 34.5 \mathrm{kV}$ interconnecting transformers. It is worth

Impact assessment of simultaneous operation of photovoltaic and cogeneration... (B. Koti Reddy) 
noting that from an operational point of view, the minimum power output of each turbine would be at least $60 \%$ of the $30 \mathrm{MW}$ (i.e. $18 \mathrm{MW}$ ). Hence, both TGs together will supply $36 \mathrm{MW}$, which is the exact active power requirement of the industry. In this industry, the management has installed a $12 \mathrm{MW}$-peak capacity SPP to meet the statutory requirements and to encourage renewable energy (RE). Furthermore, during the SPP generation time (of around five to six hours in a day), the operation of CCPP is being kept running at the lower output of around (26 MW, i.e., $13 \mathrm{MW}$ from each TG) and SPP is supplying the rest to satisfy power balance. Thus, this lowering of CCPP's output decreases the overall efficiency of the steam turbine from $34 \%$ to $32 \%$, and even the extraction of steam into the process system becomes complex.

\subsection{Solar PV power plant}

A few years ago, a 12-MW SPP was installed in the industry. The total SPP was divided into two divisions, each of $6 \mathrm{MW}$. A total of 47,060 PV modules with specifications described in Table 1 were installed with conventional inverters which do not have any reactive power support except active power output. Power evacuation was done at $6.6 \mathrm{kV}$ level through three winding transformers of 2.5 MVA, $340 \mathrm{~V} / 340 \mathrm{~V} / 6.6 \mathrm{kV}$, and Dy5y5 rating. The Levelized cost of energy was estimated to US \$ 0.113 [20].

\subsection{Operational strategy of the industry before SPP integration}

In general, the plant load demand is met by CCPP along with utility grid under floating. This is accomplished by having circuit breakers 1,2, 3 and 6, as shown in Figure 5, in closed mode. When the CCPP is 'off', the base loads of $6 \mathrm{MW}$ will be supplied by the utility grid with the help of demand management controller, which is used to curb the unwanted demand spike due to sudden turn 'on' and turn 'off' of the large induction motors.

\subsection{Operational srategy of the industry after SPP itegration}

The industry-wide power balance equation at any time $t$ is given (3) and (4).

$$
\begin{aligned}
& P^{\text {grid }}+P^{C C P P}+P^{S P P}=P^{B L}+P^{L} \\
& \mathrm{v} Q^{\text {grid }}+Q^{C C P P}=Q^{B L}+Q^{L}
\end{aligned}
$$

where, $\mathrm{P}^{\text {grid }}$, $\mathrm{P}^{\mathrm{CCPP}}, \mathrm{P}^{\mathrm{SPP}}$ denotes the active power support from the grid, CCPP, and the SPP. Also, $\mathrm{P}^{\mathrm{BL}}$ and $\mathrm{P}^{\mathrm{L}}$ represents the active power consumption by the base loads and the induction motor loads. Furthermore, in this work we have assumed the $\mathrm{P}^{\mathrm{BL}}$ as non-elastic, i.e., they are treated as constant loads. Similarly, $\mathrm{Q}^{\text {grid, }}$ $\mathrm{Q}^{\mathrm{CCPP}}$ denotes the reactive power support from the grid, and the CCPP. Also, $\mathrm{Q}^{\mathrm{BL}}$ and $\mathrm{Q}^{\mathrm{L}}$ represent the reactive power consumption by the base loads and the induction motor loads. As long as SPP is generating power, i.e., during the day time, the PV output power is thoroughly utilised by reducing CCPP generation. The following operational interlocks which are necessary for the joint management of the CCPP and SPP are presented next. If anyone TG of CCPP is tripped, the industry continues to run with support from the utility grid and SPP when it is available to satisfy (3), (4). Suppose the process load is reduced suddenly, due to any abnormality in process operations. In that case, there will be a situation of islanding of CCPP during which the SPP to be kept 'off' to avoid un-authorised power export to grid and to prevent sudden voltage rise at plant buses. For this purpose, an additional mechanical interlock is provided between the circuit breaker (CB) at GT and CB at SPP. The moment CCPP is not generating power and CB at GTs, i.e. CB-4 and CB-5 are 'off'; the mechanical interlock contact activates and trips the CBs, i.e., the CB-19 and CB-20 at SPP trips within a maximum time of 0.08 seconds (i.e., the trip time of CBs at GT and SPP together). This is well within the limits of 0.16 seconds prescribed by [6, sec.6.4.1, Tab.12].

\subsection{Under-rated operation of CCPP}

As per the characteristic curves of the steam generator and steam turbine, the performance of CCPP becomes abysmal if the generation of TG is less than $16 \mathrm{MW}$. The design efficiency of CCPP is $34 \%$ up to $16 \mathrm{MW}$ which reduce to $32 \%$ when the load is $14 \mathrm{MW}$, due to operation of SPP. The overall efficiency of CCPP is given (5).

$$
\eta^{\mathrm{CCPP}}=\frac{\text { Heat equivalent of elctrical output }}{\text { Input energy from fuel combustion }} \times 100
$$

\section{PERFORMANCE ANALYSIS AND RESULTS}

In this work, we investigated the monthly performance of 12MWpeak SPP for the last three years to know the monthly generation, temperature and irradiance effect on power output and other performance indicators as per the relevant standards, such as IEC 61724 [21]. It is also useful for comparing the PVsyst 
design's estimated output with the actual output. The leading performance indicators of a grid-connected SPP are performance ratio (PR) and capacity utilisation factor (CUF), which are illustrated as follows:

- Performance ratio (PR) is defined as the comparison between the actual energy outputs to that of theoretical energy that might have been achieved and is given (6).

$$
\mathrm{PR}=\frac{\text { Actual energy output }(\mathrm{kWh})}{\text { Theoritical output }\left(\mathrm{GA} \mathrm{APV}_{\mathrm{PV}}\right)} \times 100
$$

where Apv denotes the area of the SPP modules. It should be noted that, the PR depends on irradiance, tilt angle, and air temperature. A higher PR indicates the satisfactory operation of a plant. A PR value between $75 \%$ and $80 \%$ is reasonably good for efficient operation of SPP.

- Capacity utilization factor (CUF) is defined as the ratio between actual output to the output as per the installed capacity, which is given as (7),

$$
\mathrm{CUF}=\frac{\text { Actual energy output }(\mathrm{kWh})}{\text { Max. possible output during the time period(365*SPP installed capacity })} \times 100
$$

Moreover, CUF depends on solar irradiation, air temperature, and design quality. A higher value indicates the system running with better climatic conditions and value above $15 \%$ is reasonable. Table 3 shows the actual field values of PR and CUF and compares them with the values of design estimates. Based on this comparison, we conclude that the operation of SPP is satisfactory. A maximum energy output of 11.84 MWpeak was recorded on December 26, 2019 (i.e., a cool and bright sunny day). However, for a certain period of time the SPP was kept off either fully or partially, due to power flow restrictions from CCPP, where the minimum power output could not be maintained at steam turbine side. In the subsequent sections, we discuss the impact of such restrictions and power output of SPP due to different solar irradiance conditions.

\begin{tabular}{|c|c|c|c|c|c|c|}
\hline \multirow[b]{2}{*}{$\begin{array}{l}\text { Month and } \\
\text { Year }\end{array}$} & \multicolumn{5}{|c|}{ Generation Report from April 2017 to March 2020 in Million Units (MU) } & \multirow[b]{2}{*}{ Remarks } \\
\hline & $\begin{array}{c}\text { Estimated } \\
\text { Generation (MU) }\end{array}$ & $\begin{array}{c}\text { Actual Generation } \\
\text { (MU) }\end{array}$ & $\begin{array}{c}\text { Approximation } \\
\text { Error }(\%)\end{array}$ & PR & CUF & \\
\hline Apr 2017 & 1.483 & 1.591 & 7.28 & 86.51 & 15.42 & Good weather conditions \\
\hline May 2017 & 1.432 & 1.31 & -8.52 & 71.23 & 14.89 & Steam control issues at CCPP \\
\hline Jun 2017 & 1.23 & 0.519 & -57.80 & 28.22 & 12.79 & Steam control issues at CCPP \\
\hline Jul2017 & 0.801 & 0.958 & 19.60 & 83.07 & 8.33 & Good weather conditions \\
\hline Aug2017 & 0.89 & 1.054 & 18.43 & 80.95 & 9.26 & Good weather conditions \\
\hline Sep2017 & 1.148 & 1.393 & 21.34 & 75.74 & 11.94 & Good weather conditions \\
\hline Oct2017 & 1.344 & 1.286 & -4.32 & 69.92 & 13.98 & Steam control issues at CCPP \\
\hline Nov2017 & 1.561 & 1.24 & -20.56 & 67.42 & 16.23 & Steam control issues at CCPP \\
\hline Dec2017 & 1.54 & 1.294 & -15.97 & 70.36 & 16.02 & Steam control issues at CCPP \\
\hline Jan2018 & 1.463 & 1.205 & -17.63 & 65.52 & 15.21 & Steam control issues at CCPP \\
\hline Feb2018 & 1.59 & 1.383 & -13.02 & 75.20 & 16.54 & Steam control issues at $\mathrm{CCPP}$ \\
\hline Mar2018 & 1.686 & 1.561 & -7.41 & 84.88 & 17.53 & Steam control issues at CCPP \\
\hline Apr2018 & 1.468 & 1.656 & 12.81 & 90.04 & 15.27 & Good weather conditions \\
\hline May2018 & 1.417 & 1.39 & -1.91 & 75.58 & 14.74 & Steam control issues at CCPP \\
\hline Jun2018 & 1.217 & 0.203 & -83.32 & 11.04 & 12.66 & Steam control issues at CCPP \\
\hline Jul2018 & 0.8 & 0.845 & 5.62 & 73.27 & 8.32 & Good weather conditions \\
\hline Aug2018 & 0.89 & 0.807 & -9.33 & 61.98 & 9.26 & Good weather conditions \\
\hline Sep2018 & 1.218 & 1.234 & 1.31 & 67.10 & 12.67 & Good weather conditions \\
\hline Oct2018 & 1.33 & 1.572 & 18.20 & 85.47 & 13.83 & Good weather conditions \\
\hline Nov2018 & 1.545 & 1.541 & -0.26 & 83.79 & 16.07 & Steam control issues at CCPP \\
\hline Dec2018 & 1.524 & 1.173 & -23.03 & 63.78 & 15.85 & Steam control issues at CCPP \\
\hline Jan2019 & 1.448 & 1.547 & 6.84 & 84.11 & 15.06 & Good weather conditions \\
\hline Feb2019 & 1.573 & 1.512 & -3.88 & 82.21 & 16.36 & 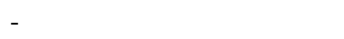 \\
\hline Mar2019 & 1.669 & 1.693 & 1.44 & 92.05 & 17.36 & Good weather conditions \\
\hline Apr2019 & 1.452 & 1.032 & -28.93 & 56.11 & 15.10 & Steam control issues at CCPP \\
\hline May 2019 & 1.403 & 1.051 & -25.09 & 57.15 & 14.59 & Steam control issues at CCPP \\
\hline Jun2019 & 1.205 & 0.327 & -72.86 & 28.36 & 12.53 & Steam control issues at CCPP \\
\hline Jul2019 & 0.785 & 1.068 & 36.05 & 82.03 & 8.16 & Good weather conditions \\
\hline Aug2019 & 0.872 & 0.988 & 13.30 & 53.72 & 9.07 & Good weather conditions \\
\hline Sep2019 & 1.125 & 1.038 & -7.73 & 56.44 & 11.70 & Steam control issues at CCPP \\
\hline Oct2019 & 1.316 & 1.393 & 5.85 & 75.74 & 13.69 & Good weather conditions \\
\hline Nov2019 & 1.529 & 1.333 & -12.82 & 72.48 & 15.90 & Steam control issues at CCPP \\
\hline Dec2019 & 1.509 & 1.42 & -5.90 & 77.21 & 15.69 & Steam control issues at CCPP \\
\hline $\operatorname{Jan} 2020$ & 1.433 & 1.505 & 5.02 & 81.83 & 14.90 & Good weather conditions \\
\hline Feb2020 & 1.557 & 1.566 & 0.58 & 85.15 & 16.19 & - \\
\hline Mar2020 & 1.652 & 1.751 & 5.99 & 95.21 & 17.18 & Good weather conditions \\
\hline
\end{tabular}

Table 3. Design estimates, actual values and performance indices of SPP from Apr. 2017-Mar. 2020 


\section{IMPACTS OF SIMULTANEOUS OPERATION OF SPP AND CCPP ON INDUSTRY'S DISTRIBUTION SYSTEM-RESULTS AND DISCUSSION}

In order to study the impacts of PV integration with co-generation captive power generation, we simulate the power network of the industry with the help of the commercial software E-TAP program. The following subsections provide a detailed discussion of the main impacts of high PV power penetration, precisely, we investigate the convergence of power flows, harmonics, reactive power, and fault currents caused due to integration of SPP along with existing CCPP on the distribution network. For brevity, the case studies are detailed;

- Case study 1: In this case study, we inv estigate the load flow of the PV-integrated distribution network using E-TAP software. It is worth to be pointed out that the load flow depicted in Figures 6-8 is singlephase, however, in E-TAP we have considered the actual three-phase model of distribution network [22].

- Case study 2: This case study investigates the harmonics injected by the smart PV converters into the distribution network. From the power-quality aspect, this case study is useful to showcase the impacts of PV-integration.

- Case study 3 and 4: The case studies 3 and 4 are the investigation into TG's power factor and fault current analysis for pre-and post-PV integration. Precisely, case study 3 discusses the power factor of TG and case study 4 analyzes the fault current contribution of the SPP for both pre-and post-PV integration. These case studies are essential to understand the sizing of capacitors to facilitate reactive power support and circuit breaker sizing in order to withstand fault currents caused by SPP.

- Case study 5: In this case study, we perform the contingency analysis for the joint management of SPP along with CCPP. This case study is helpful to understand the behaviour of the joint system during the faults and transients caused due to sudden load reduction.

\subsection{Case study-1}

The critical load point from the performance point of view of steam turbine is $13 \mathrm{MW}$. Hence, at all the times the CCPP has to supply $26 \mathrm{MW}$ load, while the remaining $10 \mathrm{MW}$ can be supplied from SPP, when it is running, and then from CCPP with a back-up from the utility grid. However, the changing power output of SPP, with varying climatic conditions are to be absorbed by CCPP, which may affect its operation. The important aspect of this work is to simulate and analyze the power flow in the industry with varying climate conditions, as we mentioned above. Figures 6-8 depicts the simulation results of pre- and post-PV integration scenarios with different irradiance scenarios, i.e., $100 \%$ and $40 \%$ solar irradiance respectively.

Based on the pre-integration simulation as depicted in Figure 6, we conclude that the power share of CCPP at $100 \%$ plant load is $60 \%$ of its capacity and is, therefore, satisfactory. Also, the voltage levels at $33 \mathrm{kV}$ and $6.6 \mathrm{kV}$ buses are at $99.98 \%$ and $103.6 \%$, respectively, which are in acceptable limits. Similarly, based on the PV integration at $100 \%$ and $40 \%$ PV levels the operation of CCPP is satisfactory, as well, with the minimum suggested loading of $13 \mathrm{MW}$ by each steam turbine. Also, the voltage levels at 33 and $6.6 \mathrm{KV}$ buses are between $100 \%$ and $104 \%$, which are well within the acceptable limit specified by [7]. It should be noted that, we have simulated case study 1 by assuming the reactive power support of the SPP to be turned off. However, in case study 3 we detail the merits of having reactive power support from SPP.

\subsection{Case study-2}

According to previously recorded industry's data, the total maximum voltage harmonic distortion (VHD) before installation of SPP, was 3.4\%. This is due to power electronics such as variable frequency drives. After SPP installation, additional harmonics are injected into the distribution system due to electronic PV inverters. In this case study, we conduct simulations for $100 \%$ PV penetration at $6.6 \mathrm{KV}$ buses-1 and 2. The total harmonic distortions (THD) at point of common coupling (PCC) where DERs are connected to the distribution network are respectively found to be $6.89 \%$ and $7.9 \%$. The above results indicate that the harmonic levels are just above 5\%; the limits are those prescribed by IEEE 519-2014 (Sec.5.1, Tab.10) [23]. To mitigate the adverse effects of harmonics caused due to SPP integration, suitable harmonic filters are suggested to be incorporated. Simulations are also done by adding additional harmonic filters inside the PV inverters (single tuned $600 \mathrm{kVAr}$ filters) with which the harmonic level has been reduced to $4.48 \%$. There exists research for proper control of grid-connected PV systems in reducing expected voltage distortion. 


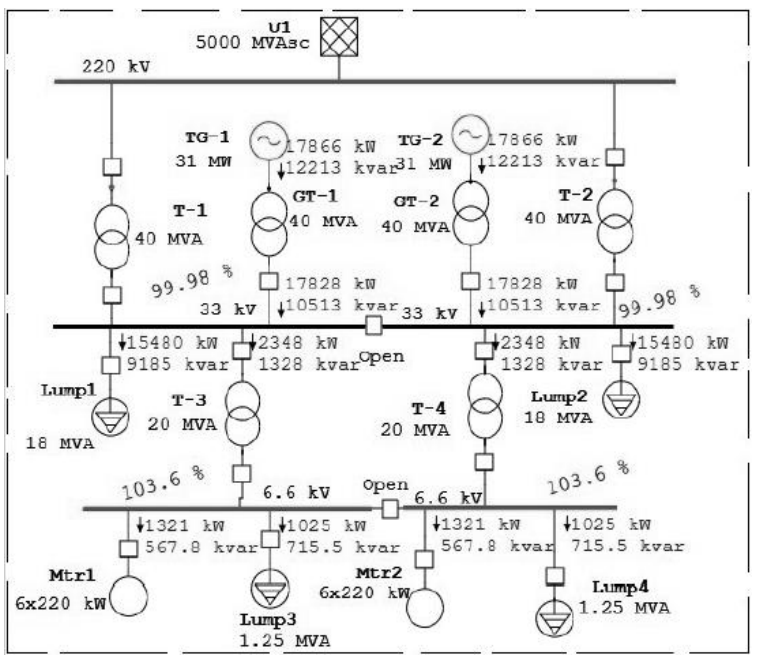

Figure 6. Pre-integration load flow

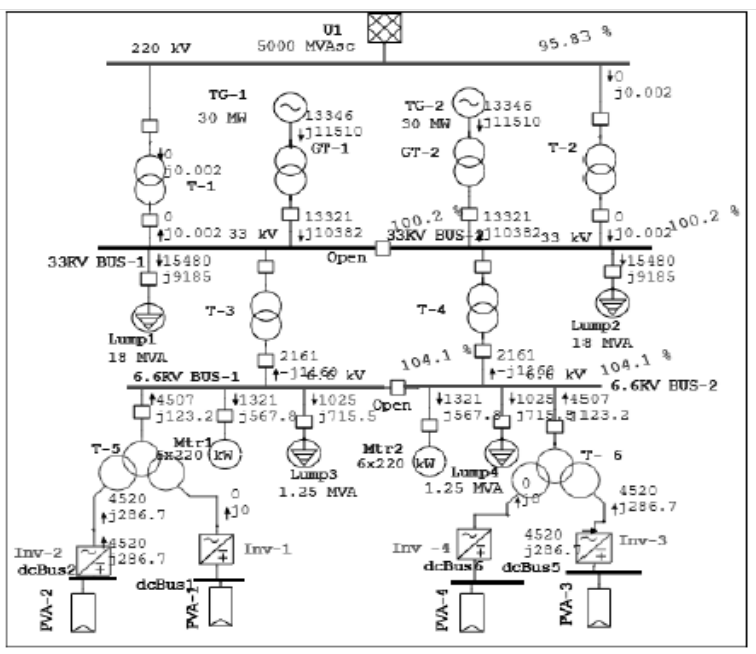

Figure 7. Post-integration load flow at irrad. of 1000 $\mathrm{W} / \mathrm{m}^{2}$

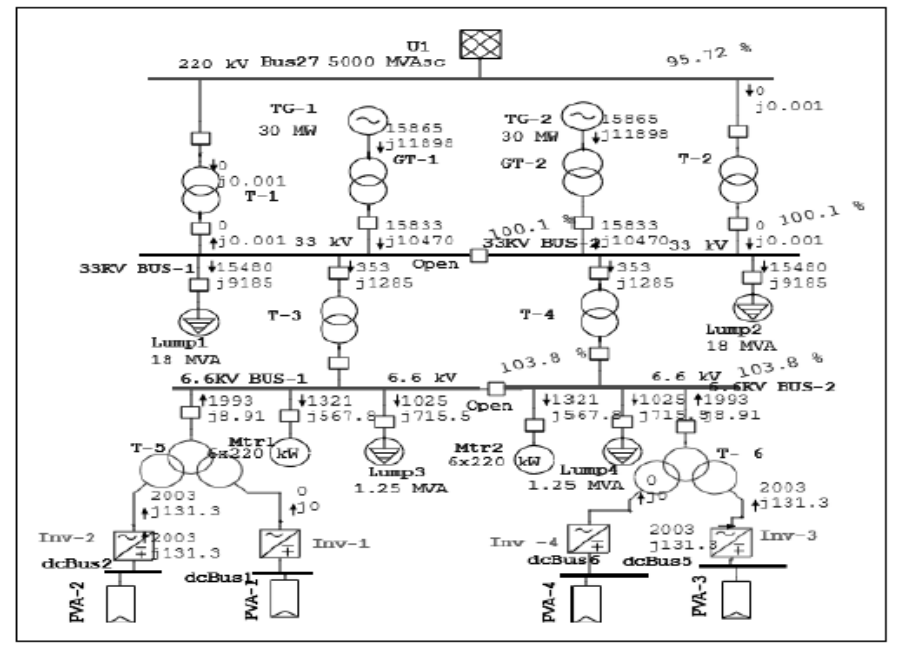

Figure 8. Post-integration load flow at solar irradiance of $400 \mathrm{~W} / \mathrm{m}^{2}$

\subsection{Case study-3}

It is a known fact that the PV system usuallyoperate close to unity power factor, i.e., they do not inject any reactive power support into the distribution system unless it has a reactive power capability. Therefore, in the current case study, we consider only the active power support from the SPP. Furthermore, to cater to the reactive power balance, the reactive power support is assumed to be provided by either CCPP or the utility grid. Hence, the power factor of CCPP or the utility grid decreases in post-integration of SPP. In this case study, simulations are performed for $100 \%$ PV penetration with utility grid disconnected, i.e., the grid-tie is assumed to be absent and therefore, the total reactive power demand is supplied only by CCPP. Before SPP integration the power factor at the CCPP is maintained at 0.83 (lagging) and with $100 \%$ $\mathrm{PV}$-integration the power factor at SPP is found to be 0.76 (lagging). This subsequently causes an increase in the line currents and have adverse effects in the system operation. To overcome this issue, we suggest the following solutions; 1) installing suitable capacitors when the power factor of the SPP is assumed to be unity 2) enabling the reactive power capability in PV inverters [24]. The former is cost-ineffective whereas the latter is cost-effective due to oversizing of the PV inverters to facilitate reactive power support. However, due to the intermittent generation of PVs, the capacitors have to work harder to regulate the power factor due to voltage fluctuations, which in turn deteriorates the life of the capacitor bank. On the other hand, the reactive power capability of PV inverters can be actively controlled without incurring much burden on the inverters, subsequently increasing the hosting capacity of renewable energy in microgrids [25]. Also, installation of storage batteries to store the PV power when it is surplus and to release the same back to loads during off-solar hours can partially eliminate the excess PV power and reactive power issues. 
The PV inverters facilitate the reactive power support given by,

$$
\left(P^{S P P}\right)^{2}+\left(Q^{s p p}\right)^{2} \leq\left(S_{\max }^{s p p}\right)^{2}
$$

where, $\mathrm{P}^{\mathrm{SPP}}, \mathrm{Q}^{\mathrm{SPP}}$ and $S_{\max }^{\text {Spp }}$ respectively denote active, reactive, and maximum apparent power capacity of SPP. The reactive power balance in (4) with $\mathrm{Q}^{\mathrm{spp}}$ is reformulated as;

$$
Q^{\text {grid }}+Q^{C C P P}+Q^{S p p}=Q^{B L}+Q^{L}
$$

Finally, simulations are conducted to understand the impacts of reactive power support provided by SPP in the joint operation. This is done by setting the power factor of PV inverter to 0.8 (lagging) in the E-TAP. The results indicate that SPPs delivered reactive power at an active power of $3 \mathrm{MW}$ i.e., $25 \%$ of rated DER capacity which is in line with the criteria mentioned in [8, Clause 5.2]. Table 4 describes the effect of reactive power support for 'on' and 'off' conditions of $\mathrm{Q}^{\mathrm{SPP}}$.

The Q-SPP off and Q-SPP on in the Table 4 corresponds to reactive power status of PV inverter, for e.g., Q-off indicates the reactive power support from the PV is turned off. Hence, the SPP operates at unity power factor (PF). From Table 4 it is evident that during Q-SPP off, the power factor at TG was maintained at 0.76 (lagging) with capacitors turned on, and the maximum voltage at $6.6 \mathrm{kV}$ bus is found to be $103.8 \%$. On the other hand, in the case of Q-SPP on, the TG power factor is maintained at 0.84 (lagging) with a percentage improvement of $10.52 \%$. This bulk improvement in power factor at TG is accomplished due to the reactive power support provided by the SPP. Furthermore, it is to be noted that the capacitor banks were turned 'off' during the Q-SPP on. Moreover, during Q-SPP on, the active power output of SPP is reduced to $3 \mathrm{MW}$ concerning 4.52 MW in Q-SPP off. This reduction in active power is negligible comparing to that of power factor improvement at TG. Also, the maximum voltage at $6.6 \mathrm{kV}$ bus is found to be $106 \%$, which is precisely meeting the limits prescribed in [7]. Therefore, the coordination study among the conventional power factor regulating devices like capacitor banks, auto-tap changers and SPPs in the industry for simultaneous operation of the SPP and CCPP is an important future research direction.

Table 4. Maximum voltage comparison by enabling reactive power support from PV inverter

\begin{tabular}{cccccc}
\hline Case & Each TG output & Each SPP output & PF@ TG & PF@ SPP & Voltage (\%) @ 6.6 kV bus \\
\hline Q-SPP off & $13.35+j 11.5$ & $4.52+j 0.286$ & 0.76 & 1.00 & 103.8 \\
Q-SPP on & $14.86+j 9.5$ & $3+j 2.25$ & 0.84 & 0.80 & 106.1 \\
\hline
\end{tabular}

\subsection{Case study-4}

To study the impact of PV penetration during a three-phase bolted fault at PCC, the system is simulated at $100 \%$ PV power level with independent feeding. The simulation results for both pre-integration and post-integration scenarios are shown in the Figures 9 and 10 respectively. This result indicate that the fault current rise is only $0.9 \%$ due to PV integration $(12.649 \mathrm{kA}$ against $12.535 \mathrm{kA}$ at $6.6 \mathrm{kV}$ bus i.e. the common point of coupling-PCC). With this result, it can be concluded that the PV integration effect on existing distribution network is not much significamt and can be manageable easily.

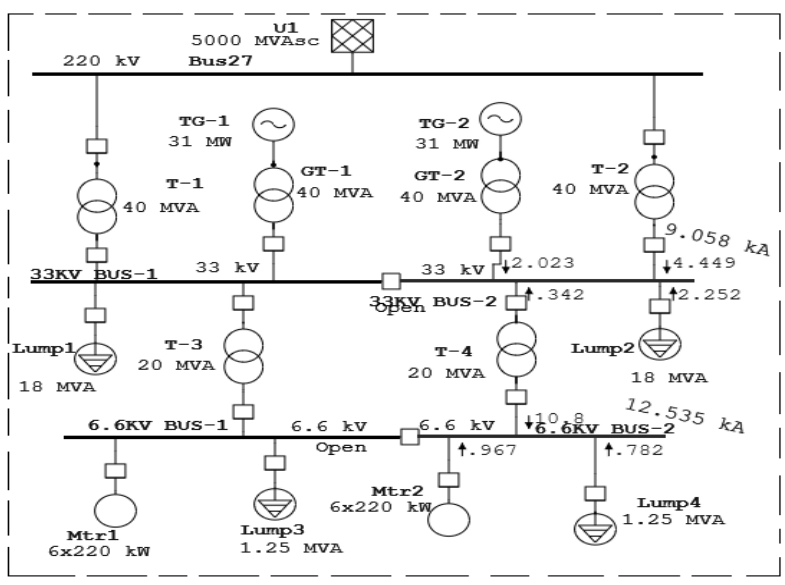

Figure 9. Fault on 6.6 and $33 \mathrm{kV}$ buses at preintegration

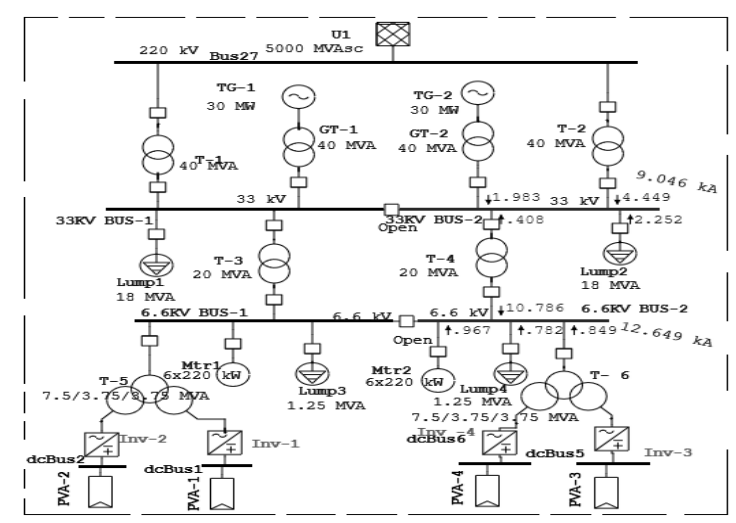

Figure 10. Fault on 6.6 and $33 \mathrm{kV}$ buses postintegration 


\subsection{Case study-5}

Contingency analysis helps to understand the power system's parameter violations during the outage of some of its components. In this study, we have carried out contingency analysis to know the system robustness, by simulating two extreme situations of; 1) sudden switching-off one TG at CCPP and 2) reduction in load to $30 \%$ on the system at $100 \%$ PV penetration. It is found that with case (1) of one TG outage; the load demand was met by other TG and parallel support from SPP and utility grids. The voltage at $33 \mathrm{kV}$ and $6.6 \mathrm{kV}$ buses are $96.7 \%$ and $101.7 \%$ respectively, which are satisfactory. Also, in the case of a sudden reduction of $30 \%$ load, the voltage at $6.6 \mathrm{kV}$ bus was $104.9 \%$ for a brief period. Simultaneously SPP got 'off' on over-voltage protection. This concludes that the system was able to withstand such transients.

\section{CONCLUSIONS}

In this work, we have conducted several case studies to understand the impacts of simultaneous operation of large-scale PV-integration on the distribution systems and co-generation captive power plants. From the case studies, we conclude that the power share of CCPP at $100 \%$ PV output is manageable or export some part of the PV generation to the utility grid or nearby industries instead of curtailing the PV power. To increase the PV penetration capacity while maintaining an acceptable power factor at CCPP, we investigated the case considering the reactive power support from the PV inverters. The harmonic study indicates that the total voltage harmonic distortion levels are marginally high and can be managed. However, any further PV additions have to be dealt with carefully by a suitable harmonic compensation program. Also, the presented case studies are simulated with E-TAP software and analyzed the effects of PV integration on power flow at different solar irradiance conditions, reactive power, fault currents, harmonic contribution, and contingency analysis as per the latest applicable IEEE standards. Finally, we have provided recommendations for satisfactory integration of SPP to large-scale industry considering CCPP. This work helps the industries integrating PV power plants in the existing network for their improved business plans. Future work will focus on improving the performance of the PV module, protective relay, installation of large size RE storage batteries and SPP-Capacitor banks coordination using optimization techniques.

\section{REFERENCES}

[1] H. Kelsey et al., "An Overview of Distributed Energy Resource (DER) Interconnection: Current Practices and Emerging Solutions," Golden, CO: National Renewable Energy Laboratory NREL/TP-6A20-72102, 2019.

[2] P. S. Revuelta, S. P. Litran, and J. P. Thomas, "Distributed Generation," in Active Power Line Conditioners: Design, Simulation and Implementation for Improving Power Quality pp. 285-322, 2016, doi: 10.1016/B978-0-12-803216-9.00008-0.

[3] S. Mills, "Combining solar power with coal-fired power plants, or cofiring natural gas," Clean Energy, vol. 2, no. 1, pp. 1-9, June 2018, doi: 10.1093/ce/zky004.

[4] REN21. "Renewables 2019 Global Status Report," L. Mastny, and J. Glave, Eds., Paris, France (Glave Communications), Editor (Paris: REN21 Secretariat), pp. 1-336, ISBN 978-3-9818911-7-1, 2019.

[5] IEEE Guide for Conducting Distribution Impact Studies for Distributed Resource Interconnection, IEEE 1547.72013, 2020.

[6] IEEE Standard for Interconnection and Interoperability of Distributed Energy Resources with Associated Electric Power Systems Interfaces, IEEE 1547-2018, 2020.

[7] IEEE Standard for Interconnection and Interoperability of Distributed Energy Resources with Associated Electric Power Systems Interfaces-Amendment 1: To Provide More Flexibility for Adoption of Abnormal Operating Performance Category III, IEEE 1547a-2020, 2020.

[8] N. Mansouri, A. Lashab, D. Sera, J. M. Guerrero, and A. Cherif, "Large Photovoltaic Power Plants Integration: A Review of Challenges and Solutions," Energies, vol. 12, no. 19, pp. 1-16, 2019, doi: 10.3390/en12193798.

[9] F. R. Badal, P. Das, S. K. Sarker, and S. K. Das, "A survey on control issues in renewable energy integration and microgrid," Protection and Control of Modern Power Systems, vol. 4, no. 8, pp. 1-27, Apr. 2019, doi: 10.1186/s41601-019-0122-8

[10] A. R Alzyoud et al., "The impact of integration of solar farms on the power losses, voltage profile and short circuit level in the distribution system," Bulletin of Electrical Engineering and Informatics, vol. 10, no. 3, pp. 1129-1141, June 2021, doi: 10.11591/eei.v10i3.1909.

[11] M. Norshahrani, H. Mokhlis, A. Abu Bakar, J. Jamian, and S. Sukumar, "Progress on Protection Strategies to Mitigate the Impact of Renewable Distributed Generation on Distribution Systems," Energies, vol. 10, no. 11, Nov. 2017, doi: 10.3390/en10111864.

[12] K. W. Nasser, S. J. Yaqoob, and Z. A. Hassoun, "Improved dynamic performance of photovoltaic panel using fuzzy logic-MPPT algorithm," Indonesian Journal of Electrical Engineering and Computer Science, vol. 21, no. 2, pp. 617-624, Feb. 2021,doi: 10.11591/ijeecs.v21.i2.pp617-624.

[13] H. Karimi, G. Shahgholian, B. Fani, I. Sadeghkhani, and M. Moazzami, "A protection strategy for inverter-interfaced islanded microgrids with looped configuration,” Electrical Engineering, vol. 101, pp. 1059-1073, Oct. 2019, doi: 10.1007/s00202-019-00841-6. 
[14] H. Hannele, "Recommended Practises for Wind and PV Integration Studies," International Energy Agency, 2nd ed, 2018.

[15] A. A. Adebiyi, I. J. Lazarus, A. K. Saha, and E. E. Ojo, "Performance analysis of grid-tied photovoltaic system under varying weather condition and load," International Journal of Electrical and Computer Engineering (IJECE), vol. 11, no. 1, pp. 94-106, 2021, doi: 10.11591/ijece.v11i1.pp. 94-106.

[16] O. F. Chamorro, D. G. Vilela, D. A. Santillan, M. D. Choque, and T. D. Leyva "Automation of the burner of a pirotubular boiler to improve the efficiency in the generation of steam," Indonesian Journal of Electrical Engineering and Computer Science, vol. 21, no. 1, pp. 101-109, Jan. 2021, doi: 10.11591/ijeecs.v21.i1.pp101-109.

[17] J. 1. Gray, "The Physics of the Solar Cell," in Handbook of Photovoltaic Science and Engineering, A. Luque, and S. Hegedus, Ed(s), II ed, USA, John Wiley and Sons, ch. 3, pp. 1-42, 2011.

[18] B. K. Reddy, and A. K. Singh, "Post PV integration protection issues," in Intelligent Circuits and Systems: Proceedings of the 3rd International Conference on Intelligent Circuits and Systems (ICICS 2020), R. Singh, and A. Gehlot, Eds., $1^{\text {st }}$ ed. Boca Raton, FL, USA: CRC Press, ch 1, pp. 1-9, 2021, doi: 10.1201/9781003129103.

[19] Y. Siregar, Y. Hutahuruk and Suherman, "Optimization Design and Simulating Solar PV System Using PVSyst Software," in 2020 4rd International Conference on Electrical, Telecommunication and Computer Engineering (ELTICOM), 2020, pp. 219-223, doi: 10.1109/ELTICOM50775.2020.923047.

[20] E. Veronese, G. Manzolini, and D. Moser D, "Improving the traditional levelized cost of electricity approach by including the integration costs in the techno-economic evaluation of future photovoltaic plants," International Journal of Energy Research, vol. 45, no. 6, pp. 9252-9269, Feb. 2021, doi: 10.1002/er.6456.

[21] IEC Standard for Photovoltaic system performance monitoring-Guidelines for measurement, data exchange and analysis, IEC 61724-1-2017, 2017.

[22] R. A. J. Khan, M. Junaid, and M. M. Asgher, "Analyses and monitoring of $132 \mathrm{kV}$ grid using ETAP software," 2009 International Conference on Electrical and Electronics Engineering - ELECO 2009, pp. I-113-I-118, 2019, doi: 10.1109/ELECO.2009.5355219.

[23] IEEE standard on recommended practice and requirements for harmonic control in electric power systems, IEEE 5192014, 2014.

[24] K. S. Ayyagari, N. Gatsis and A. F. Taha, "Chance constrained optimization of distributed energy resources via affine policies," in 2017 IEEE Global Conference on Signal and Information Processing, Montreal, 2017, pp. 1050-1054, doi: 10.1109/GlobalSIP.2017.8309121.

[25] H. S. V. S. K. Nunna, B. Azibek, A. Khamitov, P. K. Jamwal, A. K. Rathore and S. Doolla, "Increasing Hosting Capacity of Distribution Networks by Microgrid Reactive Power Management," in 2020 IEEE International Conference on Power Electronics, Smart Grid and Renewable Energy (PESGRE2020), Cochin, India, 2020, pp. 1-6, doi: 10.1109/PESGRE45664.2020.9070727

\section{BIOGRAPHIES OF AUTHORS}

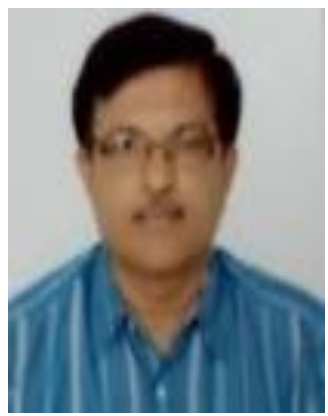

B. Koti Reddy 0000-0002-7331-6458, has more than 30 years of field experience as an Electrical engineer and involved in Installation, Commissioning, O\&M of LV/HV electrical systems, Grid-interactive solar power plant, and Electric vehicles. He has authored five book chaptersand one book titled "Electrical equipment-A field guide book" (underprint with Wiley-Scrivener Publishing). He is a senior member of IEEE.

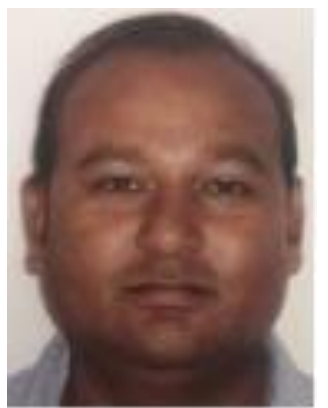

Amit Kumar Singh 0000-0003-2705-8862 (Ph.D. Electrical Engg., Scotland U.K.) graduated from REC, Durgapur, West Bengal, India, and then completed his M.S. in Electrical Power Engineering and Management from Dundee University, Scotland U.K. He is working as Associate Professor in SEEE (LPU) Phagwara. He has around 21 scientific paper publications to his credit and his research interests include Power System Reliability, Power system optimization and control. 